\title{
CrimRxiv
}

\section{Compendium of State Privacy and Security Legislation, United States, 2002-2015 (ICPSR 37826)}

United States. Bureau of Justice Statistics

Published on: Jun 29, 2021

License: Creative Commons Attribution 4.0 International License (CC-BY 4.0). 
